\title{
Air pollution and health
}

\author{
Not a crisis, but action is needed
}

The haze of photochemical smog that collects over cities has been seen by most people during hot summer spells. Media reports on adverse health effects abound, and in Britain last week the environment minister asked motorists to leave their cars at home. Is this wise advice or overreaction?

The fact that air pollution can be harmful has been accepted in Britain since 4000 excess deaths were recorded during the smog in December 1952..$^{\prime}$ The public outcry that followed led to the Clean Air Act of 1957. Air quality improved to the extent that the Clean Air Council was abolished in 1979, the Medical Research Council's Air Pollution Unit was closed a year later, and the monitoring network was largely disbanded.

Classic industrial air pollution was made up largely of smoke and sulphur dioxide from the burning of coal and generally occurred in winter. In Britain this has mainly been replaced by pollution from the combustion of petrol and diesel, which predominantly takes place in vehicles. Vehicle exhausts emit oxides of nitrogen (particularly nitrogen dioxide), carbon monoxide, hydrocarbons, particulates, and lead. On hot, still days these accumulate over cities, together with low concentrations of industrial pollutants, and undergo further reactions catalysed by sunlight to form ozone and acidic aerosols.

The health effects of this cocktail are complex and difficult to disentangle. It is widely accepted that lead can impair the neuropsychological development of children. ${ }^{2}$ The reduction of lead in petrol and financial incentives to use unleaded petrol have led to a substantial fall in the amount of lead in the environment over the past decade. Increasing traffic, however, has increased other pollutants.

Studies on the health effects of nitrogen dioxide have generally been equivocal, although an episode of severe nitrogen dioxide pollution in London in December 1991 seems to have been associated with a small excess mortality. ${ }^{3}$ On the other hand, numerous studies have found that ozone can increase bronchial responsiveness and impair lung function in a proportion of normal subjects and people with asthma. ${ }^{4}$

Exposure to carbon monoxide at the concentrations sometimes encountered in heavy traffic can raise carboxyhaemoglobin concentrations in the blood of normal subjects and can limit exercise tolerance in patients with angina pectoris. ${ }^{5}$ Studies in the United States have shown a small but consistent association between standardised mortality and concentrations of particulates in the environment, particularly those below $10 \mu \mathrm{m}$ and even below $2.5 \mu \mathrm{m}$, in comparisons between similar cities with differing levels of pollution. ${ }^{6}$ Particulates are the main pollutants emitted by diesel vehicles, which leads to the conclusion that diesel engines are no more environmentally friendly than petrol engines.

The prevalence of asthma is increasing in Western societies. Some people have blamed air pollution, but there is little evidence to support this, and the causes are unknown and likely to be multifactorial. On the other hand, air pollutants, particularly ozone, can exacerbate asthma. ${ }^{7}$ Anecdotally most patients with respiratory diseases find that atmospheric pollution, whether from cigarette smoke or vehicle exhausts, exacerbates their symptoms. If pollution can exacerbate asthma it is plausible that it plays a part in tipping some people with incipient asthma over into having clinical manifestations of the condition.

Public and media interest in air pollution over the past five years in Britain has led to a plethora of expert groups, such as the Advisory Group on Medical Aspects of Air Pollution Episodes, the Committee on the Medical Aspects of Air Pollution, the Expert Panel on Air Quality Standards, the Quality of Urban Air Review Group, the Photochemical Oxidants Review Group, the Parliamentary Office of Science and Technology, and-probably most influential of all-the Royal Commission on Environmental Pollution. ${ }^{8}$ The general consensus of these groups and their reports is that, while Britain does not have a crisis of the proportions of that in 1952 , air pollution is an important health issue. This supports the conclusion by Read and myself five years ago that even at present concentrations air pollution has detrimental effects on health. ${ }^{9}$ More monitoring and more research into the effects of the different pollutants are needed. But we have ample evidence that the quality of the air in Britain is not always ideal. We have not reached the levels of persistent pollution seen in Mexico City or Athens, but there is no room for complacency.

Improving the quality of air is not easy and requires a commitment by individuals as well as local and national regulations. The recent Environment Act has given local authorities additional powers (but no more money) to clean up the environment. The previous secretary of state for transport announced himself as the "green minister," and there are signs that the Department of Transport is beginning to take environmental issues seriously. Nevertheless, we have a long way to go in coming to terms with the internal combustion 
engine. We need a rational national transport policy, which should include making sure that each vehicle pollutes as little as possible, improved and cheaper public transport, and measures to encourage safe walking and cycling. Unrestricted expansion in our use of private cars is not sustainable. Not only must the government act but so must each of us who benefits both from the use of cars and from breathing fresh air.

Improving air quality will take time. How do we advise patients in the meantime? We can reassure them that air pollution is not a cause for panic. Patients whose respiratory disorders are made worse during pollution episodes should increase their treatment and make sure that they have adequate supplies. They could be advised to avoid optional visits to polluted cities and not to exercise, particularly in busy streets. Masks are a powerful signal to polluting drivers but probably have little protective effect.

While air pollution is a cause for concern and requires action, it is not causing a health crisis. We have, as a society, now started to come to terms with the adverse effects of the internal combustion engine, and this process is likely to gather momentum over the next decade.

MALCOLM GREEN

Consultant physician

Royal Brompton Hospital,

London SW3 6NP

Dr Green is president of the British Lung Foundation.

1 Ministry of Health. Mortality and morbidity during London fog of December 1952. London: HMSO, 1954 .

2 Baghurst PA, McMichael AJ, Wigg NR, Vimpani GV, Robertson EF, Roberts RJ, et al. Environmental exposure to lead and children's intelligence. N Engl f Med 1992;327:1279-84.

3 Anderson HR, Limb ES, Bland JM, Bower J, Ponce de Lean A, Strachan DP. Health effects of an episode of nitrogen dioxide air pollution in London, December 1991. Thorax 1994;49:1053.

4 Department of Health Advisory Group on the Medical Aspects of Air Pollution Episodes. First report: ozone. London: HMSO,1991.

5 Read $R$, Green $M$. Carbon monoxide levels in individuals occupationally exposed to vehicle exhaust. Environmental Management and Health 1991;1:7-8.

6 Dockery DW, Pope III A, Xjping XU, Spengler JD, Ware JH, Fay ME, et al. An association between air pollution and mortality in 6 US cities. N Engl f Med 1993;329:1735-9.

7 Molfino NA, Wright SC, Katz I, Tarlo S, Silverman F, McClean PA, et al. Effect of low concentrations of ozone on inhaled allergen responses in asthmatic subjects. Lancet 1991;338: concentration.

8 Royal Commission on Environmental Pollution.Transport and the environment. Eighteenth report. London: HMSO, 1994.

9 Read RC, Green M. Internal combustion and health. $B M \Im$ 1990;300:761-2.

\section{British government's proposals on poorly performing doctors}

\section{Something much more inspired and fundamental is required}

The British government earlier this week came up with a flabby and poorly written document as its contribution to the longstanding problem of poorly performing doctors (see also p 406). ${ }^{1}$ The government announced that it would do something in the autumn of 1993, after a spate of media reports about incompetent doctors. The announcement led to questions about the future of self regulation, particularly when the government had failed to find parliamentary time for the General Medical Council's proposals on dealing with doctors who performed badly.

The government promised action by the end of 1993, but the working party discovered that "achieving the deadline was always likely to be difficult as the Group quickly identified a considerable number of issues requiring consideration." Consequently the report faded into the depths of the Department of Health until being rediscovered by a new secretary of state for health presumably feeling the heat over yet another round of high profile cases of doctors performing poorly. A clue to the poor quality of the report is given in the observation that "the members of the secretariat changed during the course of meetings and preparation of the report."

The primary diagnosis of the report-that the culture within medicine and the NHS is wrong-is surely right, but the exploration of the problem is shallow and the prescription inadequate. The report contains no data and no references to the considerable worldwide experience of poorly performing doctors. The problem is that medicine has had a culture in which medical students have been humiliated for not knowing and so have learnt to hide their ignorance, in which junior doctors are reluctant to call out their seniors and so take on more than they should, in which it is seen as weakness to admit to anxieties or shortcomings, in which errors are seen as unacceptable and so are hidden, and in which all doctors find it hard to confront colleagues who are performing poorly. What's more, doctors are encouraged to think of themselves as individual professionals, dealing one to one with patients, rather than as members of teams and a part of systems that include nurses, other health professionals, and managers. In such a culture it is hard to follow the ideas of continuous quality improvement that "there are no bad people, only bad systems" and that "every defect is a treasure" (because systematic collection of defects allows constant improvement). Although individual responsibility can never be denied, dreadful cases of doctors performing poorly are most likely to be reduced not by honing the system for picking out the bad apples but rather by changing the culture to one in which all doctors accept that they could improve their practice and work continuously to do so.

But changing a culture is hard. Indeed, many management theorists doubt that managers or leaders can change a culture even within a small organisation, let alone one as large as the NHS. And the proposals of the government are desperately thin. The report recommends writing into doctors' contracts that they should take "appropriate action" when colleagues' standards of practice are poor, ensuring that all doctors know that the General Medical Council already requires such action, discussing the issue with the myriad of medical bodies, and passing legislation to allow the General Medical Council's proposals on performance review to begin (something that is now happening, with a bill going through parliament). But cultures are not changed though contracts, circulars, discussion with august bodies, and legislation.

Cultures, if they can be changed at all, are changed through outstanding leadership and through engaging day in day out with every member of the culture. Cultures are changed not from the top but from the bottom, and the art of leadership is to motivate people to want to do what needs to be done.

This is a report produced primarily so that the government can say that it is "doing something" when the next scandal breaks. Little will change. What is needed is something much more inspired and much more fundamental.

RICHARD SMITH Editor

BMJ,

London WC1H 9JR

1 Department of Health. Review of guidance on doctors' performance. Maintaining medical excellence. London: $\mathrm{DoH}, 1995$. 